\title{
Mild traumatic brain injury in children is associated with a low risk for posttraumatic seizures
}

\author{
*Anna L. Huguenard, BS, BA, ${ }^{1}$ Brandon A. Miller, MD, PhD, ${ }^{1}$ Samir Sarda, BS, ${ }^{2}$ \\ Meredith Capasse, BS, ${ }^{2}$ Andrew Reisner, MD, ${ }^{1,2}$ and Joshua J. Chern, MD, PhD ${ }^{1,2}$ \\ 'Department of Neurosurgery, Emory University; and 2Pediatric Neurosurgery Associates at Children's Healthcare of Atlanta, \\ Georgia
}

\begin{abstract}
OBJECTIVE Of the 1.7 million traumatic brain injuries (TBIs) in the US, a third occur in patients under 14 years of age. The rate of posttraumatic epilepsy (PTE) may be as high as $19 \%$ after severe pediatric TBI, but the risk for seizures after mild TBI is unknown. Although the rate of seizures after mild TBI may be low, current practice is often driven by high clinical concern for posttraumatic seizures. In this study, the authors evaluated electroencephalography (EEG) results and antiepileptic drug (AED) use in a large cohort of children with mild TBI to estimate the incidence of posttraumatic seizures in this population.

METHODS Patients presenting to Children's Hospital of Atlanta for mild TBI from 2010 to 2013 were evaluated. Five thousand one hundred forty-eight patients with mild TBI were studied and divided into 3 groups: 4168 who were discharged from the emergency department, 868 who were admitted without neurosurgical intervention, and 112 who underwent neurosurgical procedures (craniotomy for hematoma evacuation or elevation of depressed skull fractures) but were discharged without an extended stay. Demographic information, CT characteristics, EEG reports, and prescriptions for AEDs were analyzed. Long-term follow-up was sought for all patients who underwent EEG. Correlation between EEG result and AED use was also evaluated.
\end{abstract}

RESULTS All patients underwent head CT, and admitted patients were more likely to have an abnormal study $(p<$ 0.0001). EEG evaluations were performed for less than $1.0 \%$ of patients in all 3 categories, without significant differences between groups $(p=0.97)$. Clinicians prescribed AEDs in less than $2.0 \%$ of patients for all groups, without significant differences between groups $(p=0.094)$. Even fewer children continue to see a neurologist for long-term seizure management. The EEG result had good negative predictive value, but only an abnormal EEG reading that was diagnostic of seizures correlated significantly with AED prescription $(p=0.04)$.

CONCLUSIONS EEG utilization and AED prescription was low in all 3 groups, indicating that seizures following mild $\mathrm{TBI}$ are likely rare events. EEG has good negative predictive value for patients who did not receive AEDs, but has poorer positive predictive value for AED use.

http://thejns.org/doi/abs/10.3171/2015.7.PEDS14723

KEY WORDS antiepileptic drug; electroencephalography; mild traumatic brain injury; posttraumatic seizure; trauma

$\mathrm{T}$ There are up to 1.7 million emergency department (ED) visits for traumatic brain injury (TBI) annually in the US, and patients younger than 14 years old account for nearly a third of the cases.${ }^{10}$ Long-term sequelae after pediatric TBI include cognitive changes, behavioral disorders, motor dysfunction, early posttraumatic seizures, and long-term posttraumatic epilepsy (PTE). ${ }^{6,19}$

The risk of seizures following severe TBI has been studied extensively, both in adults and children. Rates as high as $19 \%$ in the pediatric population ${ }^{3}$ and $22 \%$ in the adult population have been reported, ${ }^{25}$ prompting investigation of risk factors, best clinical management, and prognosis in patients with severe TBI. However, analyses of clinical data following mild TBI are lacking. While studies in adults have shown minimal long-term seizure risk following mild TBI and possible harm from prophylactic antiepileptic drug (AED) administration, conclusions have not been made for younger patients. ${ }^{4}$

ABBREVIATIONS AED = antiepileptic drug; $\mathrm{CHOA}=$ Children's Hospital of Atlanta; $\mathrm{ED}$ = emergency department; $\mathrm{EEG}$ = electroencephalography; $\mathrm{GCS}$ = Glasgow Coma Scale; $L O S=$ length of stay; PTE = posttraumatic epilepsy; TBI = traumatic brain injury

SUBMITTED January 3, 2015. ACCEPTED July 16, 2015.

INCLUDE WHEN CITING Published online November 27, 2015; DOI: 10.3171/2015.7.PEDS14723.

* Drs. Huguenard and Miller contributed equally to this work. 
Posttraumatic seizures affect patients through multiple mechanisms: increasing or prolonging cerebral hypoxia, increasing the release of excitotoxic neurotransmitters, elevating intracranial pressure, and increasing metabolic demand in already compromised tissue. ${ }^{9,15,17}$ Younger age, greater severity of injury, mechanism of injury, loss of consciousness, skull fracture, and presence of a subdural hematoma have all been shown to be associated with higher rates of PTE following severe TBI. ${ }^{2}$

The high prevalence and morbidity of PTE following severe TBI leads to a high clinical suspicion for posttraumatic seizures in children. However, most TBI is not severe, with less than $1 \%$ of pediatric patients with TBI undergoing neurosurgical intervention. ${ }^{12}$ Clinicians typically order electroencephalography (EEG) evaluation in patients suspected of having seizurelike activity as a result of TBI. A recent study utilizing empirical EEG monitoring of pediatric patients with moderate and severe TBI found the majority to have early posttraumatic seizures. ${ }^{21}$ However, the utility of EEG following mild TBI has not been systematically investigated.

In this study we conducted a retrospective chart review to evaluate seizure risk after mild pediatric TBI (defined as Glasgow Coma Scale [GCS] score of 13 or greater at presentation). Our analysis included more than 5000 patients with mild TBI. Three patient groups allowed comparisons among those discharged from the ED, admitted without surgical intervention, and those who underwent neurosurgical procedures but fell within the established mild TBI criteria. Our results show that the risk for seizure after mild TBI is low, and suggest that EEG is of limited utility in predicting clinical management needed by this population.

\section{Methods \\ Patient Selection}

Institutional review board permission was obtained for this study, and informed consent was obtained for phone call follow-up evaluation. Children with the complaint of head injury from 2010 to 2013 at both of Children's Hospital of Atlanta (CHOA) campuses were identified through an administrative database by the point of entry into the health care system and International Classification of Diseases, Ninth Revision, codes 800-804 (fracture of skull), 850-854 (intracranial injury), and 959.09 (head injury, unspecified).

Demographic and clinical characteristics were prospectively collected in the administrative and inpatient databases, including Epic ASAP (ED application), EpicCare Inpatient (universal hospital system), EpicCare Ambulatory (outpatient medical record application), and ADT (inpatient and outpatient admission-discharge-transfer application). Data from each database was then merged into a single operational database on an Oracle platform (Oracle 11g). Sequential hospital system visits, including emergency department (ED), urgent care center, surgery department, and outpatient clinic within 180 days of discharge, were then queried and imported into a Microsoft Excel file for further analysis. The database is maintained by our institution's Business Intelligence Department. The department is staffed by computer engineers, individuals with a Masters in Business Administration degree, and nurse practitioners who institute internal data checks to ensure accuracy of reported information. We have used the same databases and similar methodology for prior studies of patients in our health care system., $7,23,26$

Demographic data fields were collected at the time of admission (index admission) and included age, primary language, race/ethnicity, zip code, and primary payer status (public assistance, self-pay vs private insurance). All of the radiology reports for each patient during the index admission were reviewed manually. Actual imaging was reviewed when the reports failed to yield needed information.

After discharge, the outpatient clinic, radiology department, operating room, and ED encounters were analyzed. Patients were cross-referenced to a complete list of EEG evaluations performed from 2010 to 2014 to identify patients clinically suspected of having seizurelike activities in the 6 months following their injury. Mild TBI was defined as patients with GCS scores of 13 or greater, with scores obtained from ED records by evaluating each patient chart. Only patients who underwent head CT in the ED were included.

A total of 5148 patients were categorized into 3 groups based on dispositions from the ED and inpatient records: 1) 4168 patients who were discharged from the ED; 2) 868 patients who were admitted for observation, did not undergo neurosurgical intervention, and had a length of stay (LOS) < 5 days; and 3) 112 patients who underwent a neurosurgical procedure with an LOS $<5$ days.

Neurosurgical procedures included elevation or repair of a skull fracture, or evacuation of a hematoma. Children with an LOS greater than 5 days were excluded, as they frequently had confounding factors causing extended hospital stays. Exclusion criteria were as follows: discharge from the ED without undergoing CT evaluation, no CT within our hospital system, transfer from an outside hospital, preexisting seizure disorder, brain tumor or other nontraumatic intracranial lesion, major extracranial injuries, and GCS score $<13$.

\section{CT Imaging}

The database included all CT imaging performed at CHOA for the identified patients described above. CT interpretations were classified as either normal or abnormal. Abnormal interpretations were further evaluated by the authors, and reports of skull fracture and intracranial injury were recorded for each patient.

\section{EEG Evaluation and Interpretation}

A comprehensive tally of inpatient and outpatient electroencephalograms (conducted at an outpatient neurology office) was available from a database maintained by the electrophysiology department. In the study period, more than 30,000 electroencephalograms were performed and interpreted by neurologists associated with our health care system, which represent all but 3 pediatric neurologists in the area. EEG studies were then cross-referenced to our list of patients with mild TBI using the unique patient 
TABLE 1. Comparison of demographic and CT scan characteristics for the 3 patient study groups after mild TBI

\begin{tabular}{|c|c|c|c|c|c|c|c|}
\hline \multirow[b]{2}{*}{ Patient Variables } & \multirow{2}{*}{$\begin{array}{l}\text { Discharged } \\
\text { From ED } \\
\text { (Group A) }\end{array}$} & \multirow{2}{*}{$\begin{array}{c}\text { Admitted w/o } \\
\text { Op (Group } \\
\text { B) }\end{array}$} & \multirow{2}{*}{$\begin{array}{c}\text { Admitted \& } \\
\text { Underwent } \\
\text { Op (Group C) }\end{array}$} & \multicolumn{2}{|c|}{$\begin{array}{l}\text { Group Comparison } \\
(\mathrm{df}=2)^{*}\end{array}$} & \multicolumn{2}{|c|}{ One-to-One Comparisons $(\mathrm{df}=1)^{\star}$} \\
\hline & & & & $x^{2}$ & p Value & Yates $X^{2}$ & $p$ Value \\
\hline No. of patients & 4168 & 868 & 112 & & & & \\
\hline Average age in mos (SD) & $98.8(69.0)$ & $64.4(64.3)$ & $78.8(58.9)$ & & $<0.0001$ & & $\begin{array}{c}<0.0001(\mathrm{~A}: \mathrm{B}) ; 0.0027 \\
(\mathrm{~A}: \mathrm{C}) ; 0.026(\mathrm{~B}: \mathrm{C})\end{array}$ \\
\hline Pts admitted to ICU (\%) & - & $85(10.0)$ & $61(54.5)$ & - & - & 152.6 & $<0.0001(\mathrm{~B}: \mathrm{C})$ \\
\hline $\begin{array}{l}\text { Pts w/ normal CT reports } \\
(\%)\end{array}$ & $3906(93.7)$ & $126(14.5)$ & $0(0.0)$ & 3067.52 & $<0.0001$ & $\begin{array}{c}2818.0(A: B) ; 1189.4 \\
(A: C) ; 17.4(B: C)\end{array}$ & $<0.0001(\mathrm{~A}: \mathrm{B}, \mathrm{A}: \mathrm{C}, \mathrm{B}: \mathrm{C})$ \\
\hline $\begin{array}{l}\text { Skull fracture only on } \\
\text { CT (\%) }\end{array}$ & $187(4.5)$ & $239(27.5)$ & $32(28.6)$ & 525.5 & $<0.0001$ & $\begin{array}{r}489.9(A: B) ; 125.4 \\
(A: C) ; 0.01(B: C)\end{array}$ & $\begin{array}{l}<0.0001(A: B, A: C) ; 0.92 \\
\quad(B: C)\end{array}$ \\
\hline $\begin{array}{l}\text { Intracranial injury on } \\
\text { CT (\%) }\end{array}$ & $75(1.8)$ & $503(57.9)$ & $80(71.4)$ & 2385.0 & $<0.0001$ & $\begin{array}{c}2223.8(\mathrm{~A}: \mathrm{B}) ; 1495.1 \\
(\mathrm{~A}: \mathrm{C}) ; 6.9(\mathrm{~B}: \mathrm{C})\end{array}$ & $\begin{array}{l}<0.0001(\mathrm{~A}: \mathrm{B}, \mathrm{A}: \mathrm{C}) ; 0.0087 \\
\quad(\mathrm{~B}: \mathrm{C})\end{array}$ \\
\hline
\end{tabular}

$\mathrm{df}=$ degrees of freedom; ICU = intensive care unit; $\mathrm{pts}=$ patients.

* An ANOVA test was used to compare patient age, with Student t-tests for group-to-group analysis. Chi-square tests were used for all other categories, with Fisher's exact tests for group-to-group analysis. All significant differences are bolded.

medical record number to capture any electroencephalograms performed within 6 months after TBI. EEG studies described as normal by the neurologist were recorded in the data as such. A record was made regarding when EEG was conducted relative to injury date and whether a patient underwent more than 1 EEG. Abnormal studies were further examined for specific findings. The relationship between EEG report and AED prescription was evaluated.

\section{AED Use}

Patients who were prescribed AEDs in the 6 months following their injury were identified through examination of each patient's chart, and the duration of AED use was recorded. To further corroborate this information, and to avoid missing patients who followed up outside our institution, telephone follow-up was attempted for all patients who underwent EEG evaluation. Calls clarified if any continuing concern for seizures existed after initial EEG, if AEDs had been prescribed, if AEDs were taken as prescribed, if and when AEDs were discontinued, and whether the child continued to visit a neurologist for seizure management.

\section{Statistical Analysis}

All data were imported from Microsoft Excel and analyzed using R statistical software (Foundation for Statistical Computing). For continuous data, comparison between groups was performed using an ANOVA, followed by the Student t-test for one-to-one analyses. For categorical data, a chi-square analysis was performed for groups, followed by Yates chi-square for one-to-one analysis if expected frequency exceeded 5 for all cells. For group comparison where the expected frequency was less than 5, a Fisher's exact test was performed instead. Contingency analysis was performed to evaluate the relationship between EEG result and AED prescription, and positive and negative predictive values of EEG for AED prescription were calculated. Significance was set at $\mathrm{p}<0.05$.

\section{Results}

\section{Patient Demographic Data by Group}

Patient characteristics are described in Table 1. Patients who were admitted for observation were typically youngest with an average age of 64.4 months $(\mathrm{p}=0.026)$. A previous analysis at our institution demonstrated an increased likelihood to admit patients less than 1 year old compared with their older counterparts with similar imaging and clinical findings following mild TBI.9 Apart from this treatment group effect, patients who received AEDs were significantly older than those who were not, according to $\operatorname{ANOVA}(\mathrm{F}[1,5146]=6.38, \mathrm{p}=0.012)$. However, there was no difference in age between children who underwent EEG compared with those who did not $(\mathrm{F}[1,5146]=0.03$, $\mathrm{p}=0.87)$.

\section{CT Imaging Characteristics in the 3 Study Groups}

All patients in this study underwent at least 1 CT scan (see above), and those results are summarized in Table 1. Patients who were discharged from the ED were more likely to have a normal CT scan than either category of admitted patients, with $93.7 \%$ being reported as normal ( $\mathrm{p}$ $<0.0001$ ). Skull fracture alone was not significantly different between categories of admitted patients $(p=0.92$, Table 1). Intracranial injury was significantly more common in admitted patients than those discharged directly from the ED ( $p<0.0001$, Table 1$)$.

\section{EEG Evaluation Following Mild TBI}

EEG evaluation in the 6 months following injury was rare in all 3 groups, with less than $1.0 \%$ of patients in any category undergoing EEG (Table 2). Notably, patients who were admitted for observation or who underwent surgery were no more likely to undergo EEG evaluation than patients discharged directly from the ED $(p=0.094)$. Some patients underwent more than 1 electroencephalogram in the 6-month time period, but this was rare (Table 2). 
TABLE 2. Evaluation of EEG results and AED use*

\begin{tabular}{|c|c|c|c|c|c|}
\hline Study Group & $\begin{array}{l}\text { Discharged } \\
\text { From ED } \\
\text { (Group A) }\end{array}$ & $\begin{array}{l}\text { Admitted w/o } \\
\text { Op (Group } \\
\text { B) }\end{array}$ & $\begin{array}{c}\text { Admitted \& } \\
\text { Underwent Op } \\
\text { (Group C) }\end{array}$ & Group Statistics & One-to-One Comparisons \\
\hline \multicolumn{6}{|l|}{ All pts (\%) } \\
\hline $\begin{array}{l}\text { Pts prescribed outpatient AEDs in the } 6 \\
\text { mos following TBI }\end{array}$ & $36(0.9)$ & $14(1.6)$ & $2(1.8)$ & $x^{2}=4.7, d f=2, p=0.094$ & $\begin{array}{c}x^{2}=3.4, d f=1, p=0.066(A: B) \\
p=1.0(A: C), p=0.89(B: C)\end{array}$ \\
\hline $\begin{array}{l}\text { Pts undergoing EEG evaluation w/in } 6 \\
\text { mos of TBI }\end{array}$ & $30(0.7)$ & $6(0.7)$ & $1(0.9)$ & $x^{2}=0.06, d f=2, p=0.97$ & $\begin{aligned} X^{2}=0.02, d f=1 p=0.89(A: B) \\
p=1.0(A: C, B: C)\end{aligned}$ \\
\hline \multicolumn{6}{|l|}{ Pts who underwent EEG (\%) } \\
\hline EEG evaluations reported as abnormal & $8(26.7)$ & $1(16.7)$ & $0(0.0)$ & $p=1.0$ & $p=1.0(A: B, A: C, B: C)$ \\
\hline $\begin{array}{l}\text { EEG report deemed "diagnostic of } \\
\text { seizure or seizure disorder" }\end{array}$ & $3(9.7)$ & $0(0.0)$ & $0(0.0)$ & $p=1.0$ & $p=1.0(A: B, A: C, B: C)$ \\
\hline $\begin{array}{l}\text { Pts who underwent }>1 \text { EEG evaluation } \\
\text { w/in } 6 \text { mos after TBI }\end{array}$ & $2(6.5)$ & $1(16.7)$ & $0(0.0)$ & $p=0.48$ & $\begin{array}{l}p=0.99(A: B) ; p=1.0(A: C, \\
B: C)\end{array}$ \\
\hline
\end{tabular}

The most common abnormality found on EEG evaluation was generalized or regional slowing. Two patients had EEG evaluations showing seizure activity or subclinical seizures during the evaluation period (Table 3). A contingency analysis comparing normal versus abnormal EEG result and AED prescription (Table 3) revealed a significant association between groups $(p<0.001)$. This relationship was strongly driven by negative results, as the calculated negative predictive value for a normal electroencephalogram was $93.1 \%$. An abnormal electroencephalogram of any type had a positive predictive value for AED prescription of $66.7 \%$. However, contingency analysis of both generalized slowing EEG reports, and spike or sharp wave EEG reports, demonstrated no relationship with AED prescription $(\mathrm{p}=0.053$ and $\mathrm{p}=0.38$, respectively). Individuals with recorded seizures during EEG testing all had subsequent AED prescriptions, and contingency analysis revealed a significant association between a diagnostic electroencephalogram and AED prescription $(\mathrm{p}=0.040)$.

\section{Prescription of AEDs Following Mild TBI}

Overall, the patients in the study had a consistently low rate of AED prescription following discharge. In all groups, less than $1.9 \%$ of patients were prescribed AEDs in the 6 months following their injury (Table 2). Importantly, patients who required admission or surgery were not any more likely to be prescribed AEDs in this time period than patients discharged directly from the ED.

To further investigate those patients who underwent EEG, phone follow-up was performed to assess medication duration and long-term suspicion for seizures. Of the 38 patients who underwent EEG evaluation, full follow-up was obtained for 36 of the patients. One patient died due to complications from a heart condition. One patient's parents were unable to be contacted. Results from follow-up are shown in Table 4.

Frequently, EEG was performed acutely after injury in response to parental or clinician suspicion. In other cases, guardian-reported seizures after discharge from the hospital prompted the evaluation (18 of 36 patients with EEG, Table 4). Some of these reported seizures were attributed to febrile seizure or a second injury (3 of 18). The best estimate of long-term seizure risk may be the number of patients who are still being managed for seizures. Only 7 of the 36 contacted patients who underwent EEG continue to see a physician for seizure management, largely from the group discharged from the ED (Table 4). Of these 7 patients, 3 had normal EEG reports and 4 had abnormal EEG reports initially after their TBI ( 2 with generalized slowing, 2 with seizures).

\section{Discussion}

\section{Risk of Seizure After Mild TBI}

The risk of seizures is likely low following mild TBI, supported by the low rate of AED use in our 5148 patients $(<1.9 \%)$. This low rate was similar across all study groups, including those who underwent neurosurgical procedures. Therefore, the need for a neurosurgical operation such as repair of a skull fracture or hematoma evacuation after mild TBI did not increase seizure risk. It is possible that we underestimate seizure risk, as we cannot detect patients who receive EEGs or AED prescriptions outside our system. However, as CHOA is the only children's hospital in our metropolitan area, and there are only 3 unaffiliated neurologists in the area, it is likely a small group that is not being detected by our analysis. It is particularly unlikely that patients who underwent surgery would seek seizure management at another institution compared with the other two study groups. Therefore, we are confident that the low risk for patients who underwent surgery accurately reflects the clinical course of their injury, and this would intuitively be the group at highest risk for posttraumatic seizures.

Our phone follow-up evaluation was targeted at children who underwent EEG evaluation, and thus our longterm data are not fully representative of our population in 
TABLE 3. EEG use and AED prescription in the 6 months following mild TBI*

\begin{tabular}{|c|c|c|c|}
\hline EEG Report & AEDs w/in 6 Mos of TBI & No AEDs Prescribed w/in 6 Mos of TBI & Totals \\
\hline Normal & 2 & 27 & 29 \\
\hline Abnormal & 6 & 3 & 9 \\
\hline Generalized or regional slowing & 3 & 2 & 5 \\
\hline Spike/sharp waves & 1 & 1 & 2 \\
\hline Diagnostic of epilepsy or partial seizures & 2 & 0 & 2 \\
\hline
\end{tabular}

* Overall correlation between normal or abnormal EEG and AED prescription was $p<0.001$. Correlation for an EEG report and AED prescription was $p=0.053$ for slowing, $p=0.38$ for spike or sharp waves, and $p=0.040$ for diagnostic of seizures.

the long term. However, it does provide more of a longterm clinical picture of those patients in whom clinical concern for seizure was highest.

\section{Clinical Utility of EEG Evaluation in Mild TBI}

Our data show that EEG results had a lower positive predictive value for AED use than negative predictive value. Patients who underwent EEG evaluation and had a normal report were less likely to receive AEDs. However, an abnormal EEG report was associated with only a $66.7 \%$ rate of AED prescription. Diagnostic EEG reports were strong predictors of AED use, but the relationship between other abnormal report types and AED prescription was not significant. These findings indicate that while a negative electroencephalogram may assist a clinician in classifying patients with low risk for recurring seizures requiring medication, an abnormal result will not provide as much guidance, unless a seizure was actively detected. Our data do not allow us to determine the rate of overuse of AEDs in children who no longer have seizures or the underuse of AEDs in patients who may have seizure activity that has escaped detection.

Our data is in contrast to that from a study showing 90\% concordance between EEG results and diagnosis of nontraumatic seizure disorders in children. ${ }^{11}$ The difference between this finding and ours could be due to institutional variability or a lower utility of EEG in the setting of mild TBI than in primary seizure disorders.
Administering EEG in the pediatric population can be time-intensive, expensive, and challenging, especially in young patients unable to cooperate. This can be worsened by the need to obtain both awake and asleep EEG, due to poor concordance of findings between the two in pediatric patients. ${ }^{16}$ In light of the low seizure risk observed in this study, in addition to an inconsistent correlation between report and management, history and clinical judgment may be better predictors of AED need than EEG studies performed shortly after mild TBI.

\section{Weaknesses of This Study}

Our conclusion that posttraumatic seizures are rare after TBI is based on the assumption that AED prescription and EEG evaluations do not occur at a significantly lower rate than posttraumatic seizures. In other words, there are not a significant number of patients in our population who are having seizures but not receiving evaluation and treatment for those seizures. While it is would appear highly unlikely that a child who developed seizures after a head injury would not return to our system to receive either EEG and/or AEDs, this study does not account for this possibility. Future prospective studies with comprehensive follow-up for all patients after mild TBI would be needed to accomplish this.

This study calls into question the utility of empirical AED use in this population. While EEG has been proven clinically useful and cost-effective for many seizure disor-

TABLE 4. Long-term follow-up with patients who underwent EEG evaluation*

\begin{tabular}{|c|c|c|c|c|}
\hline Need Head & $\begin{array}{l}\text { Discharge } \\
\text { From ED }\end{array}$ & $\begin{array}{l}\text { Admitted w/o } \\
\text { Op }\end{array}$ & $\begin{array}{l}\text { Admitted w/ } \\
\text { Op }\end{array}$ & $\mathrm{p}$ Value $†$ \\
\hline Pts w/ follow-up obtained & 29 & 6 & 1 & \\
\hline Did the child have a seizure before arriving at the hospital? (yes) & 10 & 4 & 0 & 0.18 \\
\hline Did the child have a seizure while in the hospital? (yes) & 0 & 0 & 1 & 0.028 \\
\hline Did the child have a seizure after leaving the hospital? (yes) & 16 & 1 & 1 & 0.13 \\
\hline $\begin{array}{l}\text { Did the child have a seizure after the hospital that was not described } \\
\text { as a febrile seizure, or related to a second injury? (yes) }\end{array}$ & 13 & 1 & 1 & 0.19 \\
\hline $\begin{array}{l}\text { Was the child prescribed any seizure medicine any time since the } \\
\text { injury? (yes) }\end{array}$ & 7 & 2 & 1 & 0.29 \\
\hline How long (days) did they take that medicine, if they took any? (range) & $429(7-806)$ & $228(174-282)$ & 1964 (NA) & \\
\hline Is the child currently being seen by someone for seizures? (yes) & 6 & 0 & 1 & 0.12 \\
\hline
\end{tabular}


ders ${ }^{11}$ these results may not support its use in mild TBI. It remains to be evaluated whether the risk of undiagnosed or unmanaged seizure disorder would increase if EEG use was eliminated in this population or if EEG use actually leads to false negatives and missed diagnoses of PTE in mild TBI. Ultimately, comprehensive follow-up of all patients with mild TBI would be needed to answer these questions.

\section{Future Directions}

With the widespread use of electronic medical records and greater availability of "big data," much effort has been made to improve the efficiency and cost-effectiveness of TBI care. Recent literature has shown that a low percentage of children with severe injury mechanisms require emergency neuroimaging ${ }^{20}$ and has focused on reducing the number of unneeded CT scans in children. ${ }^{8,24}$ With the negative predictive value of a normal head CT scan for neurosurgical intervention being $100 \%,{ }^{14}$ there is great incentive to reduce the number of children undergoing negative imaging because even children with mild TBI and intracranial hemorrhage are at a low risk for deterioration. ${ }^{13}$

A recent study examining 312 pediatric patients with neurologist-diagnosed PTE (defined as 2 or more unprovoked seizures) revealed that only $17 \%$ of these patients had suffered mild TBI. ${ }^{22}$ Considering that the vast majority of pediatric TBI is mild, with only $2.6 \%$ of pediatric patients with TBI requiring hospitalization, ${ }^{5}$ this study further supports the low incidence of posttraumatic seizures after mild pediatric TBI. This is in concordance with older data showing that the incidence of PTE after mild TBI to be no more than the general population, ${ }^{1}$ although the same group subsequently found an elevated incidence of PTE when examining a larger cohort of adults and children. $^{2}$

While the negative side effects of AEDs have not garnered the attention that radiation has, there is evidence that AEDs can have deleterious effects in developing children. ${ }^{18}$ Although most studies show newer AEDs have favorable side-effect profiles, it is possible that some longterm adverse effects have not been revealed. Additionally, the expense of unneeded tests and medications negatively impacts the health care system. Our study is the first to systematically evaluate the utility of AEDs and EEG in the management of children with mild TBI and indicates that routine AED and EEG use is likely inappropriate in this population. Future prospective work can help confirm these findings and reduce the costs of treating mild TBI in children.

\section{Conclusions}

Mild TBI in the pediatric population is associated with a low risk of subsequent seizures. Routine use of EEG and AEDs after mild TBI in children may not be indicated. Future prospective studies examining long-term outcomes of children after mild TBI will help improve management of this common condition.

\section{References}

1. Annegers JF, Grabow JD, Groover RV, Laws ER Jr, Elveback
LR, Kurland LT: Seizures after head trauma: a population study. Neurology 30:683-689, 1980

2. Annegers JF, Hauser WA, Coan SP, Rocca WA: A population-based study of seizures after traumatic brain injuries. $\mathbf{N}$ Engl J Med 338:20-24, 1998

3. Arango JI, Deibert CP, Brown D, Bell M, Dvorchik I, Adelson PD: Posttraumatic seizures in children with severe traumatic brain injury. Childs Nerv Syst 28:1925-1929, 2012

4. Bhullar IS, Johnson D, Paul JP, Kerwin AJ, Tepas JJ III, Frykberg ER: More harm than good: antiseizure prophylaxis after traumatic brain injury does not decrease seizure rates but may inhibit functional recovery. J Trauma Acute Care Surg 76:54-61, 2014

5. Centers for Disease Control and Prevention: Rates of TBIrelated emergency department visits, hospitalizations, and deaths-United States, 2001-2010. CDC's Injury Center: Traumatic Brain Injury. (http://www.cdc.gov/traumaticbraininjury/data/rates.html) [Accessed September 2, 2015]

6. Chapman SB, McKinnon L: Discussion of developmental plasticity: factors affecting cognitive outcome after pediatric traumatic brain injury. J Commun Disord 33:333-344, 2000

7. Chern JJ, Bookland M, Tejedor-Sojo J, Riley J, Shoja MM, Tubbs RS, et al: Return to system within 30 days of discharge following pediatric shunt surgery. J Neurosurg Pediatr 13:525-531, 2014

8. Chern JJ, Sarda S, Howard BM, Jea A, Tubbs RS, Brahma B, et al: Utility of surveillance imaging after minor blunt head trauma. J Neurosurg Pediatr 14:306-310, 2014

9. Engel J Jr, Kuhl DE, Phelps ME, Rausch R, Nuwer M: Local cerebral metabolism during partial seizures. Neurology 33:400-413, 1983

10. Faul MD, Xu L, Wald MM, Coronado VG: Traumatic Brain Injury in the United States. Emergency Department Visits, Hospitalizations, and Deaths, 2002-2006. Atlanta: Centers for Disease Control and Prevention, National Center for Injury Prevention and Control, 2010

11. Gaggero R, Pistorio A, Pignatelli S, Rossi A, Mancardi MM, Baglietto MG, et al: Early classification of childhood focal idiopathic epilepsies: is it possible at the first seizure? Eur J Paediatr Neurol 18:376-380, 2014

12. Gordon KE: Pediatric minor traumatic brain injury. Semin Pediatr Neurol 13:243-255, 2006

13. Greenberg JK, Stoev IT, Park TS, Smyth MD, Leonard JR, Leonard JC, et al: Management of children with mild traumatic brain injury and intracranial hemorrhage. J Trauma Acute Care Surg 76:1089-1095, 2014

14. Holmes JF, Borgialli DA, Nadel FM, Quayle KS, Schambam N, Cooper A, et al: Do children with blunt head trauma and normal cranial computed tomography scan results require hospitalization for neurologic observation? Ann Emerg Med 58:315-322, 2011

15. Hunt RF, Boychuk JA, Smith BN: Neural circuit mechanisms of post-traumatic epilepsy. Front Cell Neurosci 7:89, 2013

16. Kim K, Nam S: Clinical features in relation to disconcordance of sleep and waking EEG in epileptic children. J Korean Child Nerol Soc 10:63-70, 2002

17. Kochanek PM, Carney N, Adelson PD, Ashwal S, Bell MJ, Bratton S, et al: Antiseizure prophylaxis. Pediatr Crit Care Med 13 Suppl 1:S72-S82, 2012

18. Lee HS, Wang SY, Salter DM, Wang CC, Chen SJ, Fan HC: The impact of the use of antiepileptic drugs on the growth of children. BMC Pediatr 13:211, 2013

19. Matsumoto JH, Caplan R, McArthur DL, Forgey MJ, Yudovin S, Giza CC: Prevalence of epileptic and nonepileptic events after pediatric traumatic brain injury. Epilepsy Behav 27:233-237, 2013

20. Nigrovic LE, Lee LK, Hoyle J, Stanley RM, Gorelick MH, Miskin M, et al: Prevalence of clinically important traumatic brain injuries in children with minor blunt head trauma and 
isolated severe injury mechanisms. Arch Pediatr Adolesc Med 166:356-361, 2012

21. O'Neill BR, Handler MH, Tong S, Chapman KE: Incidence of seizures on continuous EEG monitoring following traumatic brain injury in children. J Neurosurg Pediatr 16:167176, 2015

22. Park JT, Chugani HT: Post-traumatic epilepsy in childrenexperience from a tertiary referral center. Pediatr Neurol 52:174-181, 2015

23. Sarda S, Bookland M, Chu J, Shoja MM, Miller MP, Reisner SB, et al: Return to system within 30 days of discharge following pediatric non-shunt surgery. J Neurosurg Pediatr 14:654-661, 2014

24. Tavarez MM, Atabaki SM, Teach SJ: Acute evaluation of pediatric patients with minor traumatic brain injury. Curr Opin Pediatr 24:307-313, 2012

25. Vespa PM, Nuwer MR, Nenov V, Ronne-Engstrom E, Hovda DA, Bergsneider M, et al: Increased incidence and impact of nonconvulsive and convulsive seizures after traumatic brain injury as detected by continuous electroencephalographic monitoring. J Neurosurg 91:750-760, 1999

26. Wrubel DM, Riemenschneider KJ, Braender C, Miller BA, Hirsh DA, Reisner A, et al: Return to system within 30 days of pediatric neurosurgery. J Neurosurg Pediatr 13:216-221, 2014

\section{Disclosures}

The authors report no conflict of interest concerning the materials or methods used in this study or the findings specified in this paper.

\section{Author Contributions}

Conception and design: Miller, Huguenard, Reisner, Chern. Acquisition of data: Huguenard, Sarda, Capasse, Chern. Analysis and interpretation of data: Huguenard. Drafting the article: Miller, Huguenard. Critically revising the article: all authors. Reviewed submitted version of manuscript: all authors. Approved the final version of the manuscript on behalf of all authors: Miller. Statistical analysis: Huguenard. Study supervision: Miller, Reisner, Chern.

\section{Supplemental Information}

\section{Previous Presentations}

Preliminary results of this study were presented at the Georgia Neurosurgical Society Meeting (May 2014), and as a poster at the 2014 CNS annual meeting (October 18-22).

\section{Correspondence}

Brandon A. Miller, 1365 Clifton Rd. NE, Bldg. B, Ste. 2200, Atlanta, GA 30322. email: brandon.miller@emory.edu. 